Fetal Diagnosis and Therapy

\title{
Is the Sequential Laser Technique for Twin-to-Twin Transfusion Syndrome Truly Superior to the Standard Selective Technique? A Meta-Analysis
}

\author{
Joost Akkermans ${ }^{a}$ Suzanne H. Peeters ${ }^{a}$ Frans J. Klumper ${ }^{a}$ \\ Johanna M. Middeldorp ${ }^{a}$ Enrico Lopriore ${ }^{b}$ Dick Oepkes ${ }^{a}$ \\ Departments of a Obstetrics and ${ }^{\mathrm{b}}$ Pediatrics and Neonatology, Leiden University Medical Center, \\ Leiden, The Netherlands
}

\begin{abstract}
Key Words
Laser coagulation - Laser therapy · Perinatal outcome ·

Twin pregnancy $\cdot$ Twin-to-twin transfusion syndrome
\end{abstract}

\begin{abstract}
Background and Objective: To investigate the efficacy of sequential laser coagulation in the treatment of twin-to-twin transfusion syndrome (TTTS). Data Sources: MEDLINE, EMBASE and the Cochrane Library were systematically searched for comparative studies on the efficacy of sequential versus standard selective laser coagulation for TTS. The primary outcome measure in these studies was survival of at least one twin, both twins and fetal demise. Results: Three cohort studies comparing the selective laser treatment technique $(n=120)$ versus the sequential technique $(n=224)$ in 344 monochorionic twin pregnancies were included. Mean survival of at least one twin was $88 \%$ in the selective group versus $92 \%(p=0.22)$ in the sequential group. Mean survival of both twins was lower in the selective group (52\%) than in the sequential group $(75 \%)$ ( $p=0.002)$. Donor fetal demise decreased from $34 \%$ in the selective to $10 \%$ in the sequential group ( $p<0.01)$, and recipient fetal demise decreased from 16 to $7 \%(p=0.02)$. Conclusion: Limited evidence suggests improved double neonatal survival as well as decreased donor and recipient fetal demise with the use of the sequential technique. However, these results are based on small non-
\end{abstract}

randomized studies with evident forms of bias and methodological limitations. A randomized controlled trial to assess the efficacy of sequential laser technique is therefore required.

(c) 2014 S. Karger AG, Basel

\section{Introduction}

Laser surgery is the accepted treatment of choice for twin-to-twin transfusion syndrome (TTTS). However, results are still far from satisfactory, with mortality rates varying from 20 to $48 \%$ [1] and significant neurodevelopmental problems in $6-18 \%$ of surviving children $[2,3]$. Important complications include iatrogenic preterm premature rupture of membranes [4] resulting in preterm delivery, twin anemia-polycythemia sequence [5] and recurrence or reversal of TTTS [6].

Since the first publications on fetoscopic laser surgery by De Lia et al. [7] in 1990, several technical and surgical modifications have been described. In 1998, Quintero et al. [8] introduced the selective laser coagulation technique and in 2007 they proposed the sequential selective laser coagulation technique [9]. The rationale for selective laser, now adopted by most fetal treatment centers, is to save as much functioning placenta tissue as possible by coagulating only true inter-twin vascular anastomoses,

\section{KARGER 125}

(c) 2014 S. Karger AG, Base

$1015-3837 / 14 / 0374-0251 \$ 39.50 / 0$ 
instead of every vessel crossing the membranous equator as was commonly done in the early years. Sequential selective laser is an adaptation of this technique whereby anastomoses are coagulated in a specific order. The theoretical benefit is to obliterate the anastomoses in a sequence that allows, at least partly, an intraoperative correction of the hypoperfusion of the donor and hyperperfusion of the recipient. This is achieved by first closing the arteriovenous anastomoses from donor to recipient, starting with the largest ones, followed by the occlusion of the arteriovenous anastomoses from recipient to donor and finally occlusion of the arterioarterial (AA) and the venovenous (VV) anastomoses, if present.

According to Quintero et al. [9], this sequential strategy improves the rate of double survival. However, the quality of evidence to support this finding is limited and well-controlled trials are lacking. Evaluation of technical or other adaptations of surgical techniques using historic controls is hampered by bias caused by increasing experience over time, the learning curve effect. In order to assess the potential benefit of this technique, we performed a meta-analysis based on the published studies comparing the sequential selective with the (standard) selective technique.

\section{Data Sources}

Prior to the meta-analysis, we created a detailed protocol that included the search strategies, inclusion and exclusion criteria, outcome parameters, and methods of statistical analysis. This meta-analysis of selective versus sequential laser in TTTS was performed according to the Meta-Analysis of Observational Studies in Epidemiology (MOOSE) [10], and Preferred Reporting Items for Systematic Reviews and Meta-Analyses (PRISMA) guidelines [11].

\section{Literature Search}

An initial literature search on studies comparing selective laser versus sequential laser was conducted in MEDLINE, EMBASE and the Cochrane Library using PubMed and OVID search engines without restriction on the language of publication. Key words and free text searches were performed with combinations of the following key words: twin-to-twin transfusion syndrome, TTTS, fetofetal transfusion, laser, laser ablation, SLPCV, SQLPCV, sequential laser, selective laser, fetoscopy, FLOC and photocoagulation. Additionally, reference sections of eligible studies were hand-reviewed for potential eligible studies.

\section{Inclusion and Exclusion Criteria}

Randomized trials and comparative studies, as well as prospective and retrospective, were considered eligible for inclusion. Reasons for exclusion were studies with irrelevant or insufficient data, letters, conference abstracts, review articles and case reports.

\section{Selection and Data Extraction}

Studies presenting data on twin pregnancies with confirmed monochorionicity by first-trimester ultrasound, affected by TTTS according to either the Eurofetus criteria [12] or the criteria described by Quintero et al. [13], treated with either selective or selective sequential fetoscopic laser coagulation of vascular anastomoses were included.

Studies were selected when presenting the number of patients treated, inclusion dates, laser technique used, survival rate of both twins, survival rate of one twin and overall survival defined as alive at 28 days after birth. Other important parameters were donor fetal demise, recipient fetal demise, gestational age at surgery and at birth and operative characteristics such as placenta localization and operating time. Studies that presented incomplete data were excluded.

\section{Primary and Secondary Outcomes}

Series were primarily analyzed for differences in survival of at least one twin, of both twins, and recipient or donor fetal demise with respect to treatment allocation. Furthermore, analyses were performed on operating time, gestational age at laser and at birth.

\section{Quality Assessment and Statistical Analysis}

All selected observational studies were assessed for the level of evidence provided according to criteria proposed by the Newcastle-Ottawa Quality Assessment Scale (NOQAS) [14]. We assessed the studies for methodological quality and appropriateness for inclusion without consideration of results. The studies were not assessed blindly. The review authors (J.A., S.H.P.) knew the authors' names, institutions and the sources of publication. We resolved disagreement by discussion until consensus was reached.

A meta-analysis was performed using Review Manager (RevMan) 5.2 Version 5.0 (The Nordic Cochrane Centre/The Cochrane Collaboration, Copenhagen 2008).

Continuous variables were reported as the median (range) or mean (SD), and for synthesis of data, medians (range) were recalculated as mean (SD) using the method described by Hozo et al. [15]. Continuous data are presented as mean differences (MD) using inverse variance statistics with $95 \%$ confidence intervals (CI). For dichoto- 
Fig. 1. Flow diagram according to the

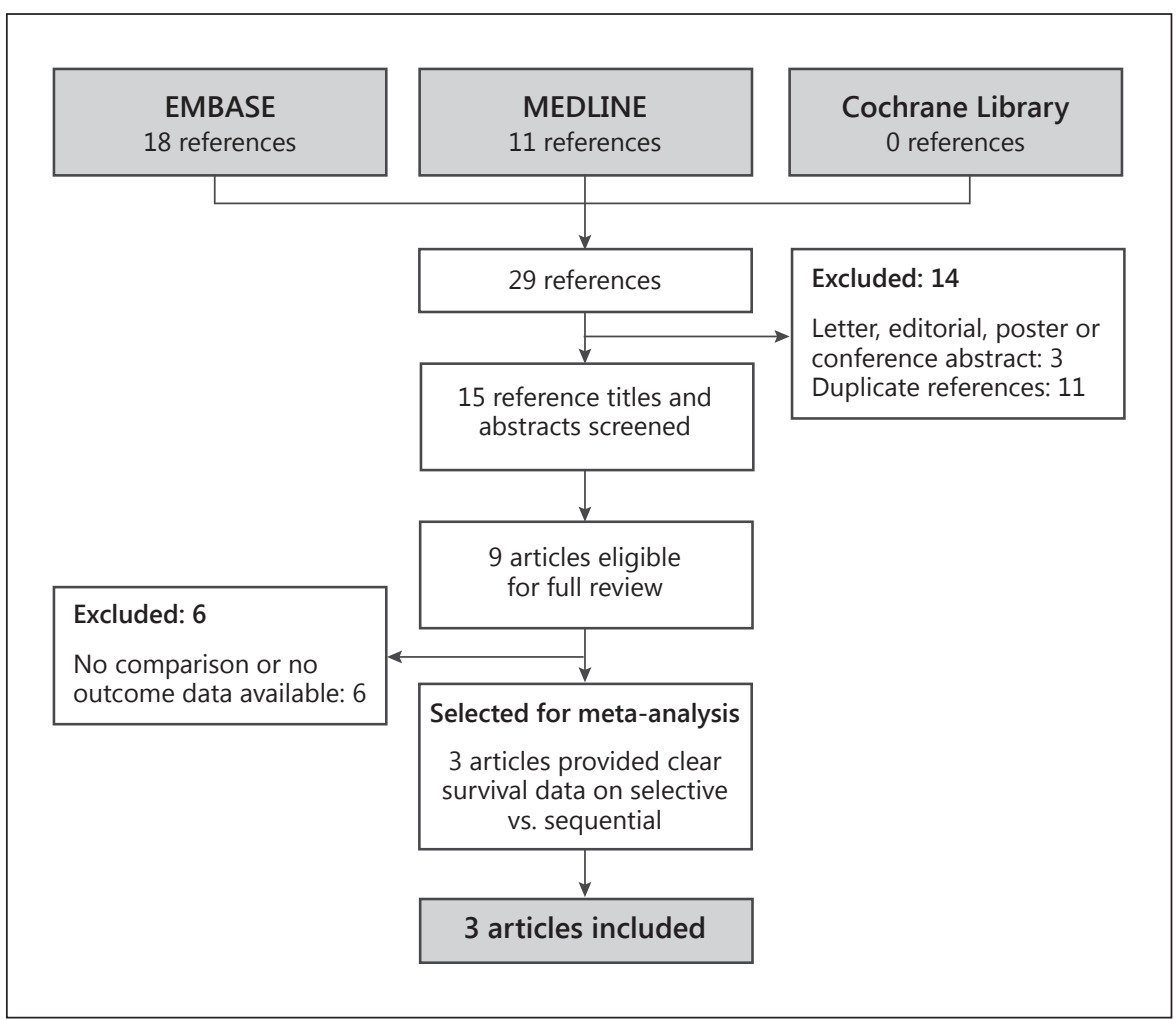

mous data, we presented results as summary risk ratio (RR) with 95\% CI.

In order to estimate the overall effect, the fixed- and random-effect models were used (significance set at $\mathrm{p}=$ $0.05)$. The $\mathrm{I}^{2}$ statistic was used to assess statistical heterogeneity. An $\mathrm{I}^{2}$ value $<25 \%$ was considered as low heterogeneity and an $\mathrm{I}^{2}$ value $>50 \%$ as high heterogeneity. In case of low heterogeneity the fixed-effects model was used.

Statistical analysis was performed using SPSS (IBM SPSS Statistics 20 for Windows; IBM, New York 2011) and MS Excel (Microsoft Excel 2010; Microsoft, Redmond 2010). Being a literature review, no approval from our ethics committee was required before performing this study.

\section{Results}

\section{Flow of Study Inclusion}

Figure 1 shows a flow diagram according to the Quality of Reporting of Meta-analyses statement [11] with the total number of citations retrieved by the search strategy and the number included in the meta-analysis. A total of three studies clearly compared selective with sequential laser technique $[9,16,17]$. These three studies were pooled for meta-analysis of survival.

Two excluded studies described sequential laser as the technique used in a proportion of their cohort but did not provide separate survival data $[18,19]$. One of the excluded studies described a cohort of patients primarily treated with sequential laser surgery [20] but did not compare this with a selective laser cohort.

\section{Study Characteristics}

None of the studies enrolled were randomized controlled trials (RCTs). The three included studies were prospective cohort studies comparing the standard selective technique to the sequential technique $[9,16,17]$. A total of 344 women were included; the study sample size ranged from 52 to 193 pregnancies. The studies were conducted in the USA and Japan. The primary outcomes, neonatal survival of at least one or both twins as well as fetal demise were well defined in all included studies.

Quintero et al. [9] prospectively compared the selective technique with the sequential technique by using the latter as intended surgery technique in all cases. All cases where the sequence could not be met due to technical 
Table 1. Characteristics of studies comparing sequential versus selective laser therapy

\begin{tabular}{|c|c|c|c|c|c|c|c|c|c|}
\hline Series & Year & Method & $\mathrm{n}$ & Period & 2 survivors & 1 survivor & $\begin{array}{l}\text { At least } 1 \\
\text { survivor }\end{array}$ & $\begin{array}{l}\text { Mean GA at } \\
\text { birth (SD) }\end{array}$ & NOQAS \\
\hline Quintero et al. [9] & 2007 & $\begin{array}{l}\text { sequential } \\
\text { selective }\end{array}$ & $\begin{array}{r}137 \\
56\end{array}$ & $2003-2005$ & $\begin{array}{r}101(74 \%) \\
32(57 \%)\end{array}$ & $\begin{array}{l}23(17 \%) \\
17(30 \%)\end{array}$ & $\begin{array}{l}91 \% \\
87 \%\end{array}$ & $\begin{array}{l}33.7(4.4) \\
33.6(4.3)\end{array}$ & 5 \\
\hline Nakata et al. [17] & 2009 & $\begin{array}{l}\text { sequential } \\
\text { selective }\end{array}$ & $\begin{array}{l}23 \\
29\end{array}$ & $2002-2006$ & $\begin{array}{l}15(65 \%) \\
10(34 \%)\end{array}$ & $\begin{array}{r}8(35 \%) \\
14(48 \%)\end{array}$ & $\begin{array}{r}100 \% \\
82 \%\end{array}$ & $\begin{array}{l}32.2(4.1) \\
31.8(4.2)\end{array}$ & 6 \\
\hline Chmait et al. [16] & 2010 & $\begin{array}{l}\text { sequential } \\
\text { selective }\end{array}$ & $\begin{array}{l}64 \\
35\end{array}$ & $2006-2008$ & $\begin{array}{l}51(80 \%) \\
20(57 \%)\end{array}$ & $\begin{array}{r}7(11 \%) \\
12(34 \%)\end{array}$ & $\begin{array}{l}91 \% \\
91 \%\end{array}$ & $\begin{array}{l}32.8(4.7) \\
31.6(4.3)\end{array}$ & 5 \\
\hline
\end{tabular}

$\mathrm{GA}=$ Gestational age (in weeks).

limitations or cases that were treated out-of-sequence were classified as standard selective.

Nakata et al. [17] prospectively compared selective versus sequential technique in a subgroup of TTTS cases complicated with absent or reversed end-diastolic flow in the umbilical artery. If the sequence of coagulation was not consistent with the defined sequence, the procedure was categorized as the standard selective laser group. If the sequence of coagulation was not recorded completely because of the difficulty of identification of blood flow direction or lack of recording, the procedure was also categorized as selective.

Chmait et al. [16] attempted a sequential laser technique in all patients. The group of patients categorized as having had selective laser failed the sequential process at some point during surgery for technical reasons. Each case was categorized as having had sequential versus selective treatment directly after surgery.

All three studies used the Quintero criteria for the diagnosis of TTTS defined as the presence of polyhydramnios (maximum vertical pocket of $\geq 8 \mathrm{~cm}$ ) and oligohydramnios (maximum vertical pocket of $\leq 2 \mathrm{~cm}$ ). The mean gestational age at time of surgery was 20.6 weeks (SD 2.3).

Two of the included studies $[9,16]$ used the sequential technique as proposed by Quintero et al. Nakata et al. [17] used a modification of this technique in which AA and VV anastomoses were occluded first.

\section{Quality of Included Studies}

The risk of bias in the observational studies was evaluated using the NOQAS (table 1). In the study by Chmait et al. [16] there were important baseline differences between the compared groups with significantly earlier gestational age at surgery $(\mathrm{p}<0.05)$, less anterior placentae $(\mathrm{p}=0.03)$ and shorter operating time $(\mathrm{p}=0.01)$ in the sequential laser group. This problem was also seen in the publication of Quintero et al. [9] with less anterior placentae $(\mathrm{p}<0.01)$, less arteriovenous anastomoses $(\mathrm{p}<0.01)$ and a shorter operating time $(\mathrm{p}<0.01)$ in the sequential laser group.

\section{Synthesis of Results}

Survival

Pooling the data of the 344 cases in the included studies, we found an increased neonatal survival of both twins from $52 \%(\mathrm{n}=62 / 120)$ after use of the selective technique to $75 \%$ $(\mathrm{n}=162 / 224)$ using the sequential technique; with an RR of 1.39; 95\% CI 1.16-1.67; $p<0.01$ (fig. 2a). No significant difference between the two techniques was observed for survival of at least one twin: $88 \%(\mathrm{n}=105 / 120)$ for the selective technique versus $92 \%(n=205 / 224)$ for the sequential technique; RR 1.05; 95\% CI 0.97-1.13; $\mathrm{p}=0.23$ (fig. 2b).

\section{Fetal Demise}

Donor demise decreased from $34 \%(n=41 / 120)$ in the selective to $10 \%(n=23 / 224)$ in the sequential group with an RR 0.34; 95\% CI 0.21-0.54; p < 0.01 (fig. 2c). Recipient demise decreased from $16 \%(\mathrm{n}=19 / 120)$ to $7 \%(\mathrm{n}=$ 15/224) after sequential treatment with an RR of 0.45 ; 95\% CI 0.22-0.88; $\mathrm{p}=0.02$ (fig. 2d).

\section{Secondary Outcomes}

Meta-analysis of secondary outcomes is shown in figure 3. Mean gestational age at surgery and at birth was 21.3 (2.4) and 32.3 (4.3) weeks in the selective group versus 20.6 (2.2) and 32.9 (4.4) weeks in the sequential group. There was a significant difference in gestational age at surgery ( $\mathrm{MD}-0.68$; $95 \% \mathrm{CI}-1.24$ to $-0.13 ; \mathrm{p}=0.02$ ) be- 


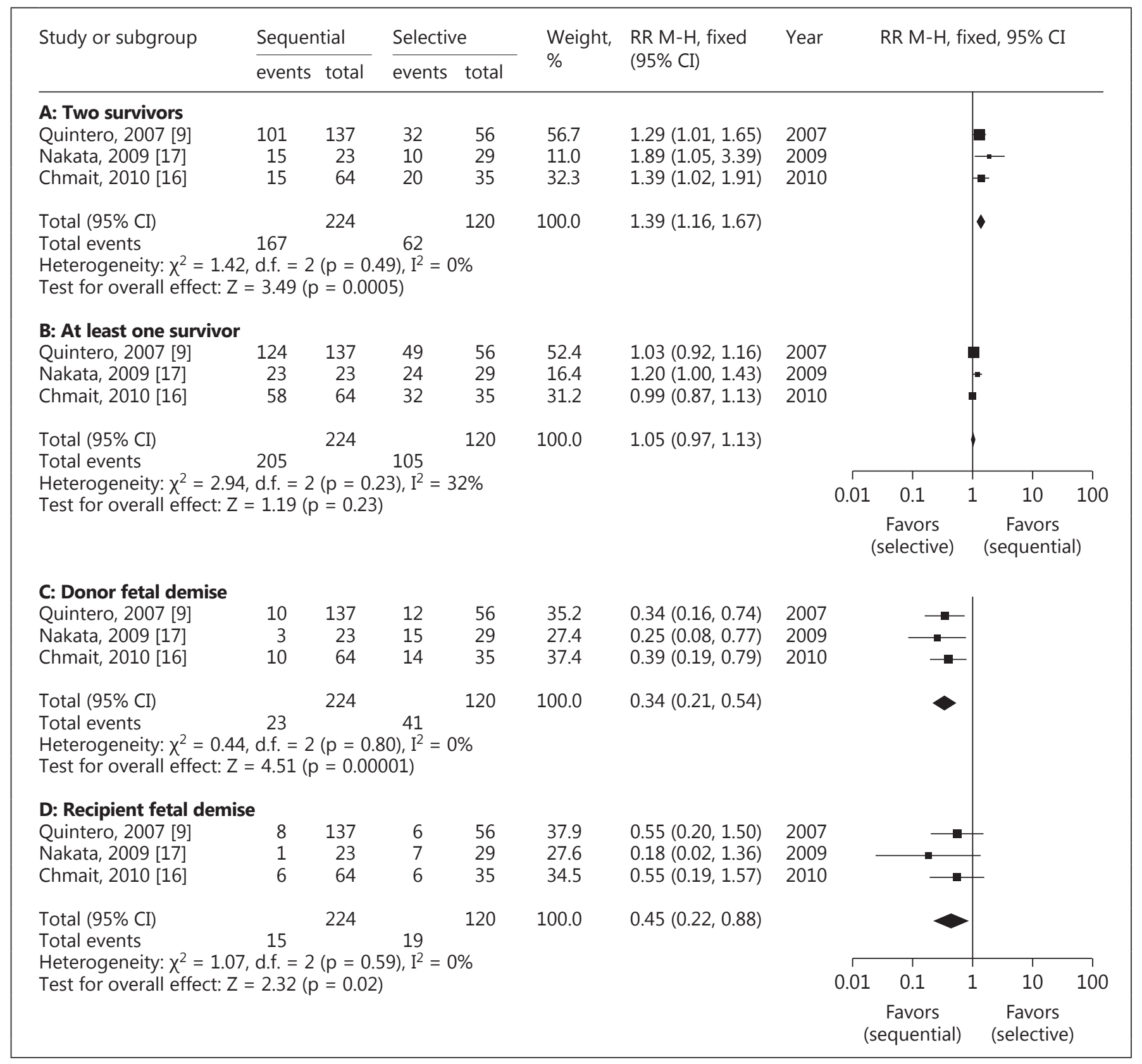

Fig. 2. Comparison of selective versus sequential laser technique, main outcomes. Effects displayed as RR using Mantel-Haenszel (M-H) statistics.

tween selective and sequential treatment but no difference in gestational age at birth (MD $0.47 ; 95 \% \mathrm{CI}-0.51$ to $1.44 ; \mathrm{p}=0.35)$.

Median operating time was $60.4 \mathrm{~min}$ (range 47.0-90.1) in the selective group and 45.4 min (range 38.0-75.2) in the sequential group. A significant difference in mean op- erating time was found between the two groups (MD $-12.16 ; 95 \%$ CI -18.22 to $-6.10 ; \mathrm{p}<0.01)$.

Sensitivity Analysis

The findings were similar whether fixed- or randomeffects models were used. 


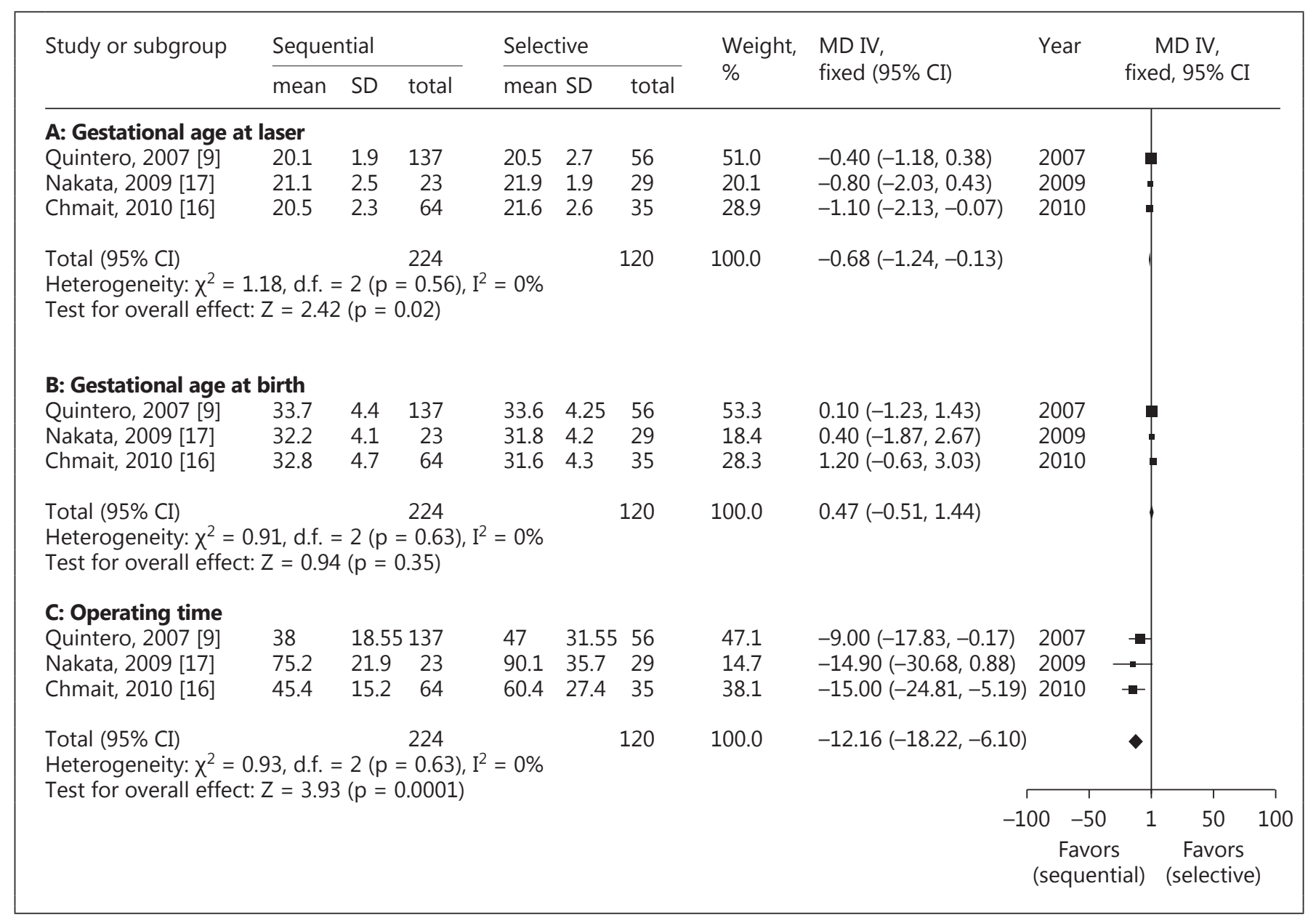

Fig. 3. Comparison of selective versus sequential laser technique, secondary outcomes. Effects displayed as MD using inverse variance (IV) statistics.

\section{Discussion}

Our meta-analysis systematically summarizes the available evidence on outcomes of MC twin pregnancies complicated by TTTS undergoing either standard selective or sequential laser treatment. Unfortunately, to date, no RCTs have been published on this subject.

\section{Primary Outcomes}

Data from three prospective cohort studies $[9,16,17]$ suggest that the sequential technique is beneficial over the standard selective technique with respect to dual survival and single fetal demise of donor or recipient. No significant difference was seen in survival of at least one fetus.

The theory behind the sequential laser technique is based on the concept of an intraoperative retrograde transfusion leading to hemodynamic stabilization or at least improvement of both twins. This could especially aid the severely hypovolemic donor resulting in less donor demise. However, concomitant acute volume depletion in the recipient twin might lead to higher recipient demise. The results from this meta-analysis show significant lower donor and recipient demise, which confirms the first hypothesis and appears to reject the latter.

However, there were considerable differences in baseline characteristics between the two groups, hampering comparability. The study design used in the three studies is prone to selection bias based on the difficulty of the procedure which is shown by a significantly higher proportion of anterior placentae and longer operating time in the selective subgroup. Furthermore, Nakata et al. [17] described a method that is slightly different from the sequen- 
tial laser technique described by Quintero et al. [9]. Instead of coagulating the arteriovenous anastomoses first, Nakata et al. [17] started with the AA and VV anastomoses. Although the underlying theory is the same, with this adaptation the theoretical protective function of AA anastomoses is omitted [21]. In their study, design allocation was dependent on the physician performing the procedure. Additionally, all cases where a full sequential technique could not be achieved or was not well recorded were categorized as standard selective. Furthermore, they only included TTTS cases with absent or reversed end-diastolic flow in the umbilical artery. Due to the above-mentioned forms of bias in the included studies, we believe that with the present available evidence, a clear benefit of sequential laser over standard selective is still lacking.

\section{Secondary Outcomes}

We found significant differences in gestational age at laser treatment which shows one of the important baseline differences due to the non-randomized nature of the studies. There was no significant difference in gestational age at birth, an important factor with respect to neonatal morbidity [22]. Another significant difference was seen in operating time. This parameter is largely influenced by the complexity of the procedure. We anticipated a longer operating time in the sequential group due to the more advanced form of placental mapping needed for this technique. In contrast, operating time was significantly lower in the sequential group, which could be explained by the above-mentioned methodology in the included studies where more difficult cases or unsuccessful sequential procedures were coded as selective procedures.

\section{Evidence-Based Medicine}

The sequential technique, where arteriovenous connections from donor to recipient are coagulated first, has gradually been adopted by an increasing number of centers. Although the rationale for this technique sounds solid, proper evidence for clinically relevant benefit is still lacking. Mathematical simulation by van Gemert et al. [23] supports the concept of sequential selective laser surgery. Nevertheless, the authors raise an important concern that the diameter of the anastomoses is an essential factor in defining the ideal sequence and that it might not always be beneficial to coagulate all arteriovenous anastomoses from donor to recipient first.

The ideal study design to assess the benefits of this technique would be randomization, with intention-totreat analysis, between sequential and standard selective laser coagulation of vascular anastomoses in TTTS. In
2010, Chmait et al. [16] mentioned that a multicenter randomized trial was in the making.

Due to the upsurge in fetal therapy centers providing laser therapy for TTTS resulting in more patients being treated, the importance of a solid evidence-based approach is essential. To date only three RCTs on laser therapy have been published. In 2004, Senat et al. [12] published an RCT comparing serial amnioreduction to fetoscopic laser ablation of placental vessels for the treatment of TTTS. This trial was stopped at the second interim analysis due to a significantly higher survival rate in the laser arm. In 2007, Crombleholme et al. [24] published data on an RCT also comparing amnioreduction to laser treatment. This trial was halted by request of the investigators due to reluctance of referring clinicians to refer to centers only offering laser treatment through randomization as part of a trial. At the same time a statistical trend in adverse outcome affecting the recipient twin in the laser treatment arm was detected that ratified the decision.

In 2014, the Solomon trial [25] was published; five European fetal therapy centers including ours randomized 274 pregnancies with TTTS to receive either the standard selective (sequential) laser coagulation or the 'Solomon' method whereby following, either selective or sequential, coagulation of the anastomoses, a line was drawn with the laser across the placenta connecting the laser spots. The new technique was found, in an intention-to-treat analysis, to significantly reduce the incidence of twin anemiapolycythemia sequence and recurrence of TTTS [25]. A study with a similar design, and likely similar numbers of patients and centers, could provide more solid evidence for a benefit of the sequential technique. Whether such an effort and associated costs are considered worthwhile is open for discussion. With a theoretical and in some studies possible benefit of sequential laser and a thus far apparent lack of disadvantages, adopting this strategy without further studies could be acceptable. However, we would urge the use of a strict, prospective quality monitoring and audit system to enable reconsideration in case of an unexpected rise of adverse events.

\section{Limitations}

The clinical relevance of these results must be interpreted with caution. No RCTs were available. Most of the included studies were prospective cohort studies with designs at risk for several types of bias, as outlined above. The only option to address such limitations is to be very careful not to draw too optimistic conclusions from the meta-analysis. 


\section{Conclusion}

The results of our meta-analysis show that there may be a true increased double survival rate and a decrease in the fetal demise of donor or recipient in pregnancies where the sequential technique was actually used compared to pregnancies treated with selective laser surgery. However, since the included studies comparing selective and sequential techniques were limited in number, and prone to several forms of bias, a possible benefit of sequential laser is still unproven.

\section{Acknowledgements}

This research is supported by the Dutch Technology Foundation STW, which is part of the Netherlands Organisation for Scientific Research (NWO), and which is partly funded by the Ministry of Economic Affairs.

\section{References}

1 Roberts D, Neilson JP, Kilby M, Gates S: Interventions for the treatment of twin-twin transfusion syndrome. Cochrane Database Syst Rev 2008;1:CD002073.

-2 Rossi AC, Vanderbilt D, Chmait RH: Neurodevelopmental outcomes after laser therapy for twin-twin transfusion syndrome: a systematic review and meta-analysis. Obstet Gynecol 2011;118:1145-1150.

-3 Van Klink JM, Koopman HM, van Zwet EW, Middeldorp JM, Walther FJ, Oepkes D, Lopriore E: Improvement in neurodevelopmental outcome in survivors of twin-twin transfusion syndrome treated with laser surgery. Am J Obstet Gynecol 2014;210: 540.e1-540.e7.

4 Beck V, Lewi P, Gucciardo L, Devlieger R: Preterm prelabor rupture of membranes and fetal survival after minimally invasive fetal surgery: a systematic review of the literature. Fetal Diagn Ther 2012;31:1-9.

5 Slaghekke F, Kist WJ, Oepkes D, Pasman SA, Middeldorp JM, Klumper FJ, Walther FJ, Vandenbussche FP, Lopriore E: Twin anemia-polycythemia sequence: diagnostic criteria, classification, perinatal management and outcome. Fetal Diagn Ther 2010;27:181-190.

6 Walsh CA, McAuliffe FM: Recurrent twintwin transfusion syndrome after selective fetoscopic laser photocoagulation: a systematic review of the literature. Ultrasound Obstet Gynecol 2012;40:506-512.

7 De Lia JE, Cruikshank DP, Keye WR Jr: Fetoscopic neodymium:YAG laser occlusion of placental vessels in severe twin-twin transfusion syndrome. Obstet Gynecol 1990;75: 1046-1053.

8 Quintero RA, Morales WJ, Mendoza G, Allen M, Kalter CS, Giannina G, Angel JL: Selective photocoagulation of placental vessels in twintwin transfusion syndrome: evolution of a surgical technique. Obstet Gynecol Surv 1998; 53:S97-S103.

-9 Quintero RA, Ishii K, Chmait RH, Bornick PW, Allen MH, Kontopoulos EV: Sequential selective laser photocoagulation of communicating vessels in twin-twin transfusion syndrome. J Matern Fetal Neonatal Med 2007;20: 763-768.
10 Stroup DF, Berlin JA, Morton SC, Olkin I, Williamson GD, Rennie D, Moher D, Becker BJ, Sipe TA, Thacker SB: Meta-analysis of observational studies in epidemiology: a proposal for reporting. Meta-Analysis of Observational Studies in Epidemiology (MOOSE) group. JAMA 2000;283:2008-2012.

11 Moher D, Liberati A, Tetzlaff J, Altman DG: Preferred reporting items for systematic reviews and meta-analyses: the PRISMA statement. Ann Intern Med 2009;151:264-269, W264.

12 Senat MV, Deprest J, Boulvain M, Paupe A, Winer N, Ville Y: Endoscopic laser surgery versus serial amnioreduction for severe twinto-twin transfusion syndrome. N Engl J Med 2004;351:136-144.

13 Quintero RA, Morales WJ, Allen MH, Bornick PW, Johnson PK, Kruger M: Staging of twin-twin transfusion syndrome. J Perinatol 1999;19:550-555.

14 Deeks JJ, Dinnes J, D’Amico R, Sowden AJ, Sakarovitch C, Song F, Petticrew M, Altman DG: Evaluating non-randomised intervention studies. Health Technol Assess Rep 2003; 7:iii-x, 1-173.

15 Hozo SP, Djulbegovic B, Hozo I: Estimating the mean and variance from the median, range, and the size of a sample. BMC Med Res Methodol 2005;5:13.

16 Chmait RH, Khan A, Benirschke K, Miller D, Korst LM, Goodwin TM: Perinatal survival following preferential sequential selective laser surgery for twin-twin transfusion syndrome. J Matern Fetal Neonatal Med 2010;23: $10-16$.

17 Nakata M, Murakoshi T, Sago H, Ishii K, Takahashi Y, Hayashi S, Murata S, Miwa I, Sumie M, Sugino N: Modified sequential laser photocoagulation of placental communicating vessels for twin-twin transfusion syndrome to prevent fetal demise of the donor twin. J Obstet Gynaecol Res 2009;35:640-647.

18 Chmait RH, Kontopoulos EV, Korst LM, Llanes A, Petisco I, Quintero RA: Stage-based outcomes of 682 consecutive cases of twintwin transfusion syndrome treated with laser surgery: the USFetus experience. Am J Obstet Gynecol 2011;204:393.e391-393.e396.
19 Sepulveda W, Wong AE, Dezerega V, Devoto JC, Alcalde JL: Endoscopic laser surgery in severe second-trimester twin-twin transfusion syndrome: a three-year experience from a Latin American center. Prenat Diagn 2007;27: 1033-1038.

20 Swiatkowska-Freund M, Pankrac Z, Preis K Results of laser therapy in twin-to-twin transfusion syndrome: our experience. J Matern Fetal Neonatal Med 2012;25:1917-1920.

21 Lopriore E, Oepkes D: Fetal and neonatal haematological complications in monochorionic twins. Semin Fetal Neonatal Med 2008; 13 : 231-238.

22 Van Klink JM, Koopman HM, Oepkes D, Walther FJ, Lopriore E: Long-term neurodevelopmental outcome in monochorionic twins after fetal therapy. Early Hum Dev 2011; 87:601-606.

23 Van Gemert MJ, van den Wijngaard JP, Lopriore E, Lewi L, Deprest J, Vandenbussche FP: Simulated sequential laser therapy of twin-twin transfusion syndrome. Placenta 2008;29:609-613.

24 Crombleholme TM, Shera D, Lee H, Johnson M, D'Alton M, Porter F, Chyu J, Silver R, Abuhamad A, Saade G, Shields L, Kauffman D, Stone J, Albanese CT, Bahado-Singh R, Ball RH, Bilaniuk L, Coleman B, Farmer D, Feldstein V, Harrison MR, Hedrick H, Livingston J, Lorenz RP, Miller DA, Norton ME, Polzin WJ, Robinson JN, Rychik J, Sandberg PL, Seri I, Simon E, Simpson LL, Yedigarova L, Wilson RD, Young B: A prospective, randomized, multicenter trial of amnioreduction vs. selective fetoscopic laser photocoagulation for the treatment of severe twin-twin transfusion syndrome. Am J Obstet Gynecol 2007; 197:396.e391-396e399.

25 Slaghekke F, Lopriore E, Lewi L, Middeldorp JM, van Zwet EW, Weingertner A-S, Klumper FJ, DeKoninck P, Devlieger R, Kilby MD, Rustico MA, Deprest J, Favre R, Oepkes D: Fetoscopic laser coagulation of the vascular equator versus selective coagulation for twinto-twin transfusion syndrome: an open-label randomised controlled trial. Lancet 2014;383: 2144-2151. 